\section{ELECTRICITY AS A MOTIVE POWER}

THE lecturer commenced by referring to the stagnation of trade, to the various remedies that had been proposed to relieve it, and to the fact that while some were maintaining and others stoutly denying that commercial depression could be cured by legislation, we were too apt to forget that there existed a means by which, without lessening the wage of the workman or means by wher, the cost of production could be diminished, prices lowered, and the failing trade of England resuscitated. He next considered the consumption of coal for various purposes yearly in Sheffield, and showed that, although the price of coal in that town was very low, being only five shillings per ton for steam coal, the total annual cost for Sheffield alone must be something like $790,000 l$. Actual instances were then given of great saving being effected by water-power being employed on a large scale for doing mechanical work. Contrasted with this, calculation showed that at the Falls of Niagara as much power was wasted as could be produced by the total present annual con. sumption of coal throughout the whole world. And when it was remembered that there existed in the world other waterfalls besides Niagara, that we had also innumerable rapidly-flowing rivers, the important fact, well known to scientific men, but one which it was so difficult to induce the world at large to grasp, stared us in the face-that we obtained in a laborious way from the depths of the earth the power we employed, and we let run to waste, every hour of our lives, many, many times as much as we used.

Again, even in a perfectly flat country, where waterfalls were unknown, the question of the economic transmission of energy had no less interest, for large steam-engines could be worked much more economically than small ones, large steam-engines requiring a consumption of only two, or two and a half, pounds, of coal per horse-power per hour, whereas small steam-engines burned eight or ten pounds, or even more. And even where large economical engines were employed there was often, as in the gigantic cotton-spinning mills in Manchester, an enormous waste of power in the shafting used in transmitting it from the engine at the base of the factory to all the different floors, and parts of each floor, a waste so great that, in spite of the extreme inefficiency of small engines, it had been proposed, as an economical measure, to replace the one large steam-engine by many small ones, each driving two or three machines direct.

The lecturer then proved numerically that (contrary to the views expressed by some people) it was impossible to use economically in a town, for motive power, the water already brought in pipes to the houses for drinking purposes, since in most towns power so produced would cost about one shilling per horse-power per hour, and although in Sheffield the great head of the water would diminish this to about fivepence per horse-power per hour, still this had to be compared with considerably less than one farthing per hour the low cost in Sheffield of producing each horse-power with a very large good steam-engine.

Experience was leading us to see that it was to electricity that we must resort to obtain a carrier that would, at a small cost, transport our motive power over long distances, and as an illustration that the electric transference of energy on a large enough scale to be of practicable value was possible, knives were ground on the platform by power conveyed about a quarter of a mile through wires carried over the houses, a Siemens's dynamo machine being employed at the one end to convert into electricity the motive power supplied by a steam-engine, and a similar but smaller Siemens's dynamo machine being used on the platform at the other end to reconvert into motive power the electric current conveyed by the wires.

The principles on which dynamo-electric machines and electro-motors act were then entered into fully experimentally, and reference was made to the first electro-motor ever madethat constructed by Salvator del Negro in 1831 -as well as to the improvements introduced into it by Jacobi, who replaced the oscillating motion by a rotatory one; different forms of modern electro-motors were then shown in action driving sewing machines, \&c. It was mentioned that although Jacobi abandoned his electro-motor used to propel a boat on the Neva because the fuel cost too much, still, that the subject of electro-motors was none the less practically important because we had since learnt why the old form was such an expensive producer of power, and what was the proper duty to be performed by electro-motors

'Abstract (by the author) of the British Association lecture delivered to 4,000 of the working-men of Sheffield, August 23, 1879, by Prof. W. E. Ayrton.
It was this very question:- Can an electric engine be made to work more economically than a steam engine? that first attracted Joule, of Manchester, in I843, to commence that all-important investigation, which lasted for six years, the determination of the mechanical equivalent of heat.

Formerly, electric currents were almost entirely produced by galvanic batteries, in which zinc was burnt just as in the furnace of a steam engine coke was burnt. The amount of heat that could be got from burning a pound of zinc could be ascertained in the same way as the amount of heat produced by the burning of a pound of coal, but the fact that the latter was about seven times the former was of little value in the science of electro-motors, until Joule had proved that a certain quantity of heat was always equivalent to exactly the same quantity of work, no matter how the heat be produced; had proved in fact that energy was as indestructible as matter, a law which had for one of its proofs the long unsuccessful search for a perpetual motion.

As a result of this law of the conservation of energy Prof. Ayrton went on to show that since a pound of ordinary coal burning gave out seven times as much heat as the burning of a pound of zinc, we might say at once, that a steam engine would give seven times as much work as an electric engine for equal weights consumed, if in both cases all the heat could be turned into work; or, since zinc was about twenty-four times as dear as coal, that a steam enoine would be about $I$ so times as economical as an electro motor, worked by a battery, if in both cases all the heat were converted into work.

But so far, he said, "we have only considered the law of 'Conservation of Energy.' There is, however, another, and no less important, principle called the 'Dissipation of Energy ;' and this law tells us that although the energy of a system cannot by itself increase or diminish, yet our power to convert one form of energy into another is continually growing less, our stock of available energy is gradually failing. Our mountain Iakes, our vast store of coal, are practically useless until either the water is set in motion rolling down the hillside, or until the particles of the coal are set in rapid vibration as it slowly burns; energy of position, energy of chemical affinity, are of no use to the manufacturer until turned into kinetic energy or energy of motion. But from friction of various kinds, whenever energy exists in the kinetic form, some portion of it is being continually converted into heat. Whenever man or nature utilises energy it must be first turned into some kinetic form, and whatever be the aim of the special machinery employed some of this energy passes into heat. We cannot make even a clock go without regular winding up, although the only useful work done by the clock is to turn its hands at regular speeds; the earth's energy of rotation is now, like the moon's in past ages, gradually growing less, and is being converted into heat on account of tidal retardation; the earth, moon, and sun, and all the planets are losing their energies of motion and relative positions, to be all ultimately turned into heat.

"But at any rate, it will be said, there will still remain the heat, and since heat can be converted back into other forms of energy, we shall be none the worse off. But it must not be forgotten that whenever heat is produced some passes off by conduction through even our best non-conducting substances, and by radiation into space from even our best non-radiating surfaces; and this conducted and radiated heat, although it may impart some trifling warmth to unseen worlds, is for the greater part entirely lost to our universe. And even were it not so, even had we perfectly non-conducting coatings, and perfectly non-radiating surfaces-had we, in fact, the most perfect heat engine that our study of the science of heat would lead us to believe theoretically possible, one with no friction, no loss of heat by conduction through the sides of our cylinders, and no radiation from their surfaces-still our power to convert heat into other forms of energy would be very limited. For if there are two bodies, one hotter than the other, we can employ an engine, like a steam. engine, to convert part of the heat in the hotter one into some other form of energy ; but the amount of heat converted, with even this ideal perfect engine, will, with such temperatures as are met with in practice, only be $a$ fraction of what necessarily passes through the engine from the hot body to the cold, and warms up the latter; and as our whole power of conversion of heat into work depends on the difference of temperature, we lose it altogether when we have brought all parts of a system to the same temperature, no matter how high this temperature may be.

"It is not, therefore sufficient to say that the burning of a pound of coal produces seven times as much heat as the burning of a 
pound of zinc; but we must consider what fraction of the heat thus produced is converted into useful work in a heat and in an electric engine respectively.

"As already mentioned, our most perfect steam.engines can be made to produce one-horse power with the consumption of $2 \mathrm{lbs}$. of coal per hour. Now, the burning of $2 \mathrm{lbs}$, of coal will produce enough energy to raise $18,528,000$ pounds one foot, or will produce $18,528,000$ foot pounds of work. Now, one-horse power is equivalent to $1,980,000$ foot pounds of work per hour; therefore, as regards the total energy in coal, even our best steam-engines only utilise $\frac{2}{\sigma}$ of it, and waste $\frac{\tau}{6}$. But, as already mentioned, even a perfect engine camnot, with the ordinary temperature available, utilise the whole of the heat of the fuel. In fact, theory tells us that the efficiency of a perfect heat engine, or the ratio of the work done to the maximum work obtainable from the consumption of the fuel, is equal to the ratio of the number of degrees of temperature through which the steam is cooled in doing work to the highest temperature of our steam, when we take as our zero of temperature a point $460^{\circ}$ below the ordinary zero of the Fahrenheit scale.

"Now, in our best steam-engines, the steam, when it begins to push the piston by expanding, has a temperature of about $300^{\circ} \mathrm{F}$., and at the end of the stroke a temperature of $100^{\circ} \mathrm{F}$., so that the efficiency of a perfect ideal engine working between these temperatures is only about ${ }_{4}^{1}$, not so very much greater than that of best practical engines.

"No great advance can be made, then, in a heat engine, except by making the temperature of the working substance, steam, gas, or whatever it may be, much higher. If, for example, we could raise the temperature of the working substance as high as, say, $3,000^{\circ} \mathrm{F}$., the temperature of combustion, and could make it leave the engine without artificial cooling at the ordinary temperature of the air, which is, say, $60^{\circ} \mathrm{F}$., then a perfect heat engine, under these conditions, would only waste about $\frac{1}{7}$ of the total energy; consequently, assuming that we could, at these high temperatures, make a practical engine as good relatively to an ideal perfect engine as we can at lower temperatures, then a practical engine would only waste $\frac{7}{45}$ of the total energy, or would have an efficiency of about 0.84 .

"But, with our present knowledge, to work with steam or gas at a temperature of $3,000^{\circ} \mathrm{F}$. is almost as ideal as an engine with no friction and with no loss of heat by conduction and radiation. We are, therefore, led to the conviction that as it is solely by working with steam at very high temperatures that the efficiency of steam-engines can be seriously increased, it may be well to consider whether it is not possible to economically replace the steam engine with some other form of motor."

It was then proved theoretically and experimentally that whenever an electro-motor is being worked by an electric current it is acting as a magneto-electric machine and producing a reverse current tending to stop the motion.

The lecturer then explained that, when an electro-motor is worked by a given galvanic battery, calculations lead us to the result that if we wish to produce the work most economically we must, by diminishing the load on the motor, allow its speed to increase until the reverse current it produces is only a little smaller than that sent by the battery; in fact, until the current circulating through the arrangement is very small, in which case the efficiency of the engine, or the ratio of the work it produces in a given time to the maximum work it could produce from the same consumption of material is nearly unity. If, on the other hand, we desire a given battery to cause the motor to do work most quickly, independently of the consumption of material, then calculation teils us that we onght to put such a load on the motor that its speed will send a reverse current equal to something like a half of the strength of the current the battery could send through the motor when at rest. In this case the efficiency is about $\frac{1}{2}$, or balf the energy is wasted in heat

He impressed upon the andience that the difference between these two considerations of maximum values ought carefully to be borne in mind, especially as it was usually the second-or how to obtain work most quickly - that had generally been taken into account, whereas it was the other one-or how to transmit work most economically, that would specially engage their atten. tion during the lecture.

And in connection with the latter maximum value?he said, "Let us consider that we work our motor in the most efficient waythat is very fast with a small load, and let us suppose as an extreme case that by so doing the efficiency is so little short of unity that we may regard it as one; then since an electro-motor worked by a battery in which zinc is burnt is 150 times as costly to maintain as a steam engine for equal efficiencies, the best electromotor worked by such a battery will be thirty-three times as dear as our best steam engines having an efficiency of $\frac{2}{9}$. We may, therefore, throw on one side at once all idea of electro-motors worked by ordinary batteries, even although the electro-motors be perfect. Now, this result is most important, since it shows not that an electro-motor as a machine is inefficient, but it tells us that attempting to drive it with a galvanic battery is the hopelessly inefficient part of the arrangement.

"But if we turn to the question of using electro-motors for the transference of power, then there is no difficulty about burning zinc, and the high efficiency of such motors is all important.

"For in the case of natural sources of power, such as waterfalls, we have merely to consider what amount of energy will be produced at the distant factory; will it be sufficient to repay the expense of putting up wires from the source to the factory, together with the cost of the two dynamo-electric machines, or will it be cheaper to put up and use a small steam engine having probably an efficiency of only $\frac{1}{18}$ ?

"When the distance between the source and the motor is considerable, the cost of putting up the leading wires becomes important, and the question therefore arises, can two or more people use the same leading wires without increasing the thick. ness, or must the thickness of the wire be so much increased as to make the construction of two sets of leads as economical?"

Prof. Ayrton explained that he attached great importance to this question because the answer to it would decide whether the electric transmission of power was a mere dreamer's fancy, or was likely to have a real commercial future.

A detailed examination was then made of the laws governing the transmission of energy by water power, and as a result of the fact that the energy of a flow of water depends on the quantity and on its head it was shown that, as far as the waste of power by friction of the fwater in the pipes was concerned, a great pressure in the reservoir sending a small current to turbines in a town also working at great pressure was an extremely economical mode of transporting power, but that if we took into account the in efficiency of existing engines for producing a great pressure of water at the reservoir, combined with the great waste of power arising from even small leakages that were certain to be caused by the great water pressure, it followed that the system was an impracticable one.

An examination was then made of the laws governing the electric transport of energy, and the lecturer arrived at this result : -

"Just as we concluded in the case of the water, that the most efficient method to employ in order to transfer the energy, was great pressure in the reservoir, combined with turbines in the town working at a high pressure, so now we conclude that the most efficient way to transfer energy electrically is to use a generator producing a high electromotive force, and a motor producing a return high electromotive force; and by so doing the waste of power in the transmission ought, I consider, be able to be diminished with our best existing dynamo-electric machines to about 30 per cent.; for, as experiment shows the efficiency of our best existing dynamo-machines to be 0.86 (that is 86 per cent. of the power spent in revolving the bobbins is reproduced as energy of electric current); therefore, if two similar dynamo-electric machines be coupled up to transmit power, and if they are worked most economically in the general way I have already explained, and with the details of arrangement that I will enter into later on, instead of being worked so that the motor gives out power most rapidly, I have reason for expecting that the combined efficiency of the arrangement can be made to closely approach the square of 0.86 , and not merely one-half, as commonly supposed.

"But while the two solutions of the problem are thus identical, there is this most important difference: increasing the pressure of the water means an uneconomical task, while increasing the electromotive force set up by a dynamo-electric machine, or an electro-motor, means merely running it faster, or running it at the same speed and putting more wire on the rotatory portion.

"And again, assuming that the mean electromotive force between the wire and the earth be as much as one hundred times the electromotive force producing the current, namely, the difference between the electromotive forces of the generator and of the motor, then with the ordinary insulation of the best land telegraph lines, less than one per cent. of the energy transmitted ten miles would be lost by leakage. 
"It would be impossible to increase indefinitely the speed of revolution of the cylinder of an induction machine, since apart from mere mechanical friction the iron constituting the core of the revolving part has to be magnetised and demagnetised very rapidly as it revolves. Now, there is a physical limit to the speed with which this can be done, and in addition this rapid change of magnetism heats the iron very much. But experiment shows that at the ordinary speed of revolution of dynamo-electro machines, 700 turns per minute, the electromotive force is proportional to the speed. We are, therefore, very far yet from the limit of speed. Consequently it would be well for the transmission of power to attempt first, a considerable increase of speed in the generator, combined with so light a load on the motor, that its speed is also very high. When this begins to fail as larger and larger amounts of power are transmitted, then we might begin increasing the amount of wire on the revolving coils of each ; but this, of course, bas the objection that the loss of power from a given current would then become somewhat larger.

"In some of the dynamo-electric machines, the current that is sent through the external wires is the same as that which circu. lates round the fixed electro-magnets to create the magnetic field in which the movable coils revolve. Now, the small current which I am here advocating should pass between the generator at the one end of the line, and the electro-motor at the other, would be too small to properly magnetise the fixed electromagnets of the two machines, so that even a high speed of the bobbin will not produce a high electromotive force. But this difficulty is easily overcome by the plan already employed, for totally different reasons, by Gramme, Lontin and Wilde, in their generator for producing currents for electric lighting, viz., that of using either a separate exciter, or a separate portion of the revolving bobbin in the generator, to produce the current to magnetise the fixed electro-magnets. In connection with this current for exciting the fixed magnets, it is worthy of notice in passing, to observe that since experience shows that the electromotive force of a dynamo-electric machine is proportional to the velocity, I conclude that the magnets are saturated, and that the exciting current is already too strong, so that it may be with advantage reduced, or many fewer coils of wire employed in this portion of the machine.

"We have then been led to this most important result which I hope is clear to you all, and which I trust you may all carry away with you-that a dynamo-electric machine, with a separate exciter, driven very fast with a steam engine, or with a stream of ruater, at high or lowe pressure, and sending, by even quite a fine veire, a small current to a distant electro-motor, also muning very fast and magnetised by a separate exciter, is an cconomic arrangement for the transmission of power."

An examination was then made of the way this result was affected by increasing the length of the connecting wires, and it was proved that the electric transmission of power was not only practical, but also very economical, both for short and long distances, if the generator of the electric current at one end of the line and the motor, worked by this electric current, at the other end of the line, were both run fast enough, and if only we required to transmit a sufficiently large quantity of power.

The lecturer then went on to say, "We have been considering the transport of power derived more especially from natural sources; but since we have seen that by the use of electricity, properly employed, the waste of power in transmission can be reduced for any distance to about 30 per cent. of the whole power absorbed at the generator, it follows that the employment of steam-engines of vast size at points outside Sheffield would be by far the most economical mode of extracting the energy out of coal. For it is at least four times as expensive to produce power with a small steam-engine as with a large one ; therefore, including the waste of power in electric transmission, the cost of production of power in small workshops would be little more than one-third as dear as if small steam-engines were used, and similarly the waste of power in any large mill or factory in its transmission from the large steam-engine at its base to all the floors and machines on each floor would be very much diminished.

"Consequently it would be much more economical to work this lathe on the platform, as I will now proceed to do, by a big steam-engine in Howard-street, several hundred yards away, than to use a small steam-engine here for this purpose."

He then reminded them that not only can electricity produce motive power, but also light and heat, and electric heating and lighting had this great advantage, that no chimneys were required. Experiments were then made of boiling water and lighting the Albert Hall by an electric current generated a quarter of a mile away.

Reference was then made to the great money-saving of some thing like 30 s. an hour, that Dr. Siemens had been able to effect at the Albert Hall, London, by replacing the old gas jets by electric lamps giving even more light, and to the unexpecte advantage attained by the present stillness of the air arising from the use of the electric light, and which enabled the singing and music there to be better heard now. Great weight was attached to the fact that at the Albert Hall the science of hanging a brilliant light high up had been luckily allowed to ride over the precedent of putting a number of feeble glimmers all over a building, and in connection with this it was explained that the reason why electric lighting for streets had been economically much less successful, was because English conservatism had prevented the authorities from realising the possibility of using for street electric illumination anything differing from an ordinary iron lamp-post. Attention was then drawn to the fact bearing most closely on the economy of electric lighting on a large scale, and which had been obtained as the result of experiments, that the larger were the dynamo machines used for producing the electric light, the more light was produced per horse-power. Taking all this into consideration, Prof. Ayrton arrived at the result that "at any rate we may be absolutely safe in saying that the cost of using gas in Sheffield for lighting large halls, such as the one we are now in, factories, and the streets could be halved if electric currents, generated by water engines worked by hill streams, as well as by very large steam engines, were substituted for gas.

"But can this be"quite right," for I have proved that to transfer energy economically we must use a large pressure and a small flow. Now, how can we produce a very bright electric light with a small current? Why, by not using the current that comes along the wire to produce the light at all, but merely to drive an electro-motor, which motor, at the place where any laroe amoun: of light was required, would be employed in giving motion to a second dynamo-electric machine, which would produce the currents for lighting purposes.

"This experiment I might show you, but as we have used already several times during the evening electric lights fed from a distance, we will vary the experiment and try an analogous one. Messrs. Walker and Hall will now, at their works, give rapid motion to a dynamo-machine, and the current which, when properly arranged, as $I$ have explained to you, may be small, will set in motion this electro-motor. This in its turn will cause this other dynamo machine to rotate rapidly and produce a current which I will use for rapidly gilding this piece of plate."

Calculation showed that if electric currents generated by very large steam engines at certain points, and by turbines driven by the falling water on the hillsides round Sheffield, were substituted for the use of coal for motive power, smelting, heating, and lighting buildings, that a saving of something like $400,000 \%$. a year might be anticipated for that town; and as an argument to prove that although such a reform was startling in its economical bearing, it might nevertheless be sound, the following was adduced:- Imagine the cost of cutlery and plated goods to remain as at present, but all machinery to be removed from Sheffield', then what an enormous loss would accrue to the town frorn everything having to be done by hand labour. The saving then which the lecturer was showing the audience how to obtain, enormous though it might be, was still small compared with the gain that the introduction of machinery during the last hundred years had effected for that town.

Next was considered whether the Sheffield Water Company had any water in their reservoirs that could be spared for producing motive power, since of course the water which did work at its source would lose head and so be unable to come to the tops of the houses in the town as at present, and it was shown that there was a considerable surplus supply. As an illustration of such a use of the water power, a two inch board was sawn or the platform by a circular saw, driven by an electric current generated by a water engine in the yard of the Water Works, and conveyed to the Hall by wires crossing the streets.

As a practical illustration of what had been done the lecturer said :- "Last year two French engineers, MM. Chrétien and Felix, at Sermaize (Marne), actually ploughed fields by electricity, the electric current being produced by two dynamo-electric machines, of a form invented by $M$. Gramme, and shown in the diagrams on the walls. These maachines were tsually worked 
with a steam engine at some convenient place three or four hundred yards away in an adjoining road, and the electro-motors were also two Gramme machines, one on each side of the field, with their coils revolving of course backwards. Through one of these, the electric current was sent alternately, so that motion was given to one or other of two large windlasses, one on each of the waggons containing the electro-motors. In this way the plough, which could be used going in either direction, was first pulled across the field making a furrow, and then back again making another parallel furrow."

A photograph taken on the spot, of one of the complete Gramme electro-motors, with its windlass and waggon, together with the double acting plough, was projected on to the screen.

A second photograph was also now projected on to the screen of M. Chrétien's electric crane for unloading boats. This too, the lecturer said, had been stuccessfully employed for several months at Sermaize, in the harbour there, and it was considered that a saving of about thirty per cent. had been effected of the expense formerly incurred for unloading the sugar barrels out of the boats.

Reference was then made to the difficulty that would be experienced in distributing electric power properly on account of the current in any curcuit being affected by any alteration in any otber circuit connected with it, and it was explained how this difficulty was met by the electric current regulations of M. Hospitalier and Dr. Siemens, Another difficulty arising from the velocity of the water on the hill streams being great after floods and small in dry weather, and which at first sight might appear to require an extravagant supply of dynamo machines so that even in a draught sufficient power could be transmittted electrically, it was explained, could be overcome by storing up the electric energy as compressed gas, and it was shown that a square foot of hydrogen at thirty atmospheres pressure (the usual pressure in the iron gas bottles of commerce) combining with half a cubic foot of oxygen, at the same pressure, would develop no less than I Io million foot pounds of work.

Prof. Ayrton concluded by asking :-

"But is there no other side to this question? We are, it is true, commercial people, but do we not still love our hills and our ficlds? There was a time when the cutler of now black, grimy, Sheffeld was very fleet of foot in following the chase. There was a time when 'Not only in the villages around old Sheffield,' so says the history of Hallamshire, 'were the filemakers' shops or the smithy to be seen, with the apprentices at work; but even on the hill side in the open country, at the end of the barn would be the cutlers' shed whilst in the valley below, by the river, was the grinding wheel ready to sharpen the tools that had been manufactured.'

"And why not now? why should not that mountain air that has given you workmen of Hallamshire in past times your sinew, your independence of character, blow over your grindstone now Why should not division of labour be carried to its end and power brought to you instead of you to the power? Let us hope then that in the next century electricity may undo whatever harm steam may have done during the last, and that the future workman of Sheffield will, instead of breathing the necessarily impure air of crowded factories, find himself again on the hill side, but with electric energy laid on at his command."

\section{THE ANTIQUITY OF MAN}

$\mathrm{A}^{\mathrm{T}}$ the Sheffield meeting of the British Association Prof. $A$ Boyd Dawkins, in the course of a paper "On the Antiquity of Man," said he presented before them a diagram showing the divisions of the tertiary period, the third of the three great life periods which had been presented on the earth. When he examined those stages before the highest forms of life, he was confronted with this most important fact : in the eocene age they had not a single species of placental mammal, nor did they meet with any indications of a living placental genus. No species now fuund in Europe were found in the eocene age. It was absolutely imposible to suppose that man was living on the earth in eucene time, yet there was no reason, because of climate and vegetation, that he should not have been. Then they came to the miocene age, when they found not merely living families and orders, but living genera. Putting man out of the question, there was not a single well-authenticated case on record in any part of the world of any mammalian species now living on the earth having lived in the miocene age. The French preserved a flint flake which was found at Thenay, and which they say is of the miocene age; in fact it was accepted by a great majority of the French archrologists that man was living in the miocene age. The French held that flints found, and all of them bearing traces of manufacture, were of the miocene age, and the work of man. It was far less difficult to believe that these flints were the work of some of the bigher and extinct forms of mokeys, than it was to believe that they were the work of man. In the pliocene age they found one or two living species making their appearance. Prof. Capelini had called attention to the fact that certain cut bones, which were asserted to be of the miocene age, had been cut by the hand of man. On one of those bones there were cuts which were done by the hand of man. The cuts were distinctly artificial, but the difficulty which presented itself to his mind was this. He was by no means certain that those bones, which were said to have been found in the pliocene strata, had been discovered in undisturbed pliocene strata. It was not clear to his mind that the mineralisation of those bones would not take place long after the pliocene age had passed away. He urged his objections to the accepting of specimens said to have been got in the pliocene age when there was no good authority for saying that such was the case. He then passed to the pleistocene, by some called the glacial period. Then living species were very abundant, extinct species very rare, and it was in that age that they met with man in considerable abundance and scattered over a very wide area. The evidence presented from time to time, in the first place out of caverns, and on the other hand out of river deposits, showed beyond a doubt that man was present in Europe in full force in the pleistocene age, and he came in just when it might be expected he would come in. In the pleistocene age they met with man as a mere hunter, not as a farmer or possessor of wild animals. He mentioned that because during the last two or three years it had been asserted that man was possessed of domestic animals in the pleistocene period. The pre-historic period which succeeded the pleistocene, was characterised by the absence of the extinct species of mammalia, with one exception. The one extinct animal which extended upward into the prehistoric age was the Irish elk. The great characteristic of the pre-historic age was the calling in of the domestic animals, the dog, sheep, horse, various breeds of hog, cattle-all coming in under the care of man, all spreading over Europe; and along with them they had the getting of cereals and fruits, and the cultivation of the arts of agriculture. They had in that period just those very things which formed the foundation of that civilisation which they themselves spread, and which had been built upon the foundations of the neolithic age. The pre-historic period was divided into the neolithic, the bronze age, and the age of iron. The pre-historic age was divided from the historic, because the former was not represented to them in historic records. In conclusion he ventured to express an opinion as to how happy they would be if they could get hold of a date and fix the antiquity of man in Europe in terms of years. It wonld be most delightful if they could fix the first presence of man at Creswell Crags, say within some thousands or hundreds of thousands of years. He could not help thinking that all their hopes of that description would be vain, as there were intervals, and they could not know without the written record, the duration of the intervals which separated one period from another.

\section{UNDERGROUND TEMPERATURE -}

THE temperature of the surface of the ground is not sensibly influenced by the flow of heat upwards from below, but is determined by astronomical and atmospheric conditions. The rate of increase in travelling downwards from the surface may conveniently be called the temperature gradient, and averages about $x^{\circ} \mathrm{F}$. for fifty or sixty feet. This is about five times as steep as the temperature gradient in the air.

If we draw isothermal surfaces for mean annual temperature in the ground, their form beneath mountains and valleys will be flatter than that of the surface above them. This is true even of the uppermost; and the flattening increases as we pass to lower ones, until at a considerable depth they become sensibly horizontal planes. The temperature gradient is consequently steeper beneath gorges and least deep beneath ridges.

In a place where the surface of the ground and the isothermal surfaces beneath it are horizontal the flow of heat will be vertical,

$\mathrm{I}$ "On some Broad Features of Underground Temperature," by Prof. J. I "On some Broad Features of Underground Temperature, by Prof D. Everett, F. R.S.
British Association. 